\title{
History, mechanisms and clinical value of fibrillation analyses in muscle denervation and reinnervation by Single Fiber Electromyography and Dynamic Echomyography
}

\author{
(1) Amber Pond, (2) Andrea Marcante, (3) Riccardo Zanato, (3) Leonora Martino, (3) Roberto \\ Stramare, (4) Vincenzo Vindigni, (5,6) Sandra Zampieri, (6) Christian Hofer, (6,7) Helmut \\ Kern, (2) Stefano Masiero, (8) Francesco Piccione
}

(1) Anatomy Department, Southern Illinois University School of Medicine, Carbondale, IL USA; (2) CIR-Myo, Rehabilitation and Physical Medicine Unit, Department of Neurosciences, University of Padova, (3) CIR-Myo, Radiology, Department of Medicine, University of Padova, (4) CIR-Myo, Plastic Surgery, Department of Neuroscience, University of Padova, Italy; (5) CIR-Myo, Department of Biomedical Sciences, University of Padova, Italy; (6) Ludwig Boltzmann Institute of Electrical Stimulation and Physical Rehabilitation, Vienna, Austria; (7) Department of Physical Medicine and Rehabilitation, Wilhelminenspital, Vienna, Austria; (8) Clinical Neurophysiology, San Camillo Hospital I.R.C.C.S., Venezia-Lido, Italy

\begin{abstract}
This work reviews history, current clinical relevance and future of fibrillation, a functional marker of skeletal muscle denervated fibers. Fibrillations, i.e., spontaneous contraction, in denervated muscle were first described during the nineteenth century. It is known that alterations in membrane potential are responsible for the phenomenon and that they are related to changes in electrophysiological factors, cellular metabolism, cell turnover and gene expression. They are known to inhibit muscle atrophy to some degree and are used to diagnose neural injury and reinnervation that are occurring in patients. Electromyography (EMG) is useful in determining progress, prognosis and efficacy of therapeutic interventions and their eventual change. For patients with peripheral nerve injury, and thus without the option of volitional contractions, electrical muscle stimulation may be helpful in preserving the contractility and extensibility of denervated muscle tissue and in retarding/counteracting muscle atrophy. It is obvious from the paucity of recent literature that research in this area has declined over the years. This is likely a consequence of the decrease in funding available for research and the fact that the fibrillations do not appear to cause serious health issues. Nonetheless, further exploration of them as diagnostic tools in long-term denervation is merited, in particular if Single Fiber EMG (SFEMG) is combined with Dynamic Echomyography (DyEM), an Ultra Sound muscle approach we recently designed and developed to explore denervated and reinnervating muscles.
\end{abstract}

Key Words: skeletal muscle, denervation, atrophy, fibrillation, clinical electromyography, Single Fiber EMG (SFEMG), dynamic echomyography (DyEM)

Eur J Trans Myol - Basic Appl Myol 2014; 24 (1): $41-54$

Skeletal muscle fibrillation refers to small, local muscular contractions that occur in response to spontaneous activation of single muscle fibers which then contract independently of surrounding fibers. This activity contrasts with muscle fasciculations which occur when muscle fibers of a motor unit are stimulated and contract in a synchronous manner. ${ }^{1-3}$ Spontaneous fibrillations have been described in cases of certain muscle disorders such as muscular dystrophy, ${ }^{4}$ polymyositis ${ }^{5,6}$ and amyotrophic lateral sclerosis, $^{2,7}$ conditions in which muscle fiber regeneration and /or denervation are often or very often present. ${ }^{8,9}$ However, they are considered to be a defining characteristic of motor nerve disruption to the skeletal muscle fiber in humans 10-15 and in animal models of spinal cord injury (SCI) and peripheral denervation. ${ }^{1,3,16-18}$ These spontaneous fibrillations are often used clinically to determine the severity and magnitude of neural injury ${ }^{19-21}$ and nerve regeneration status. $^{22}$ It also has been proposed that these fibrillations could be useful in assessing the muscle 


\section{News on skeletal muscle fibrillation analyses}

Eur J Trans Myol - Basic Appl Myol 2014; 24 (1): 41-54

atrophy occurring subsequent to denervation. ${ }^{11,23} \mathrm{We}$ would like to add the mechanism of pre-neural stages of muscle fiber development that are mandatory events of muscle fiber regeneration. ${ }^{24}$

\section{History}

The first recorded observations of muscle fibrillations after denervation have been attributed to Schiff ${ }^{25}$ who reported, in his 1851 article entitled "Ubermotorische Lahmung der Zunge," visual observations of fibrillations in the tongue muscles of dogs after bilateral hypoglossal nerve section. In 1915, experiments by Langley and Kato ${ }^{26,27}$ were the first to show explicitly that fibrillations followed denervation. Interestingly, three years later Langley and Hashimoto, ${ }^{28}$ in continued experiments along the same vein, arguably may have come close to observing length dependency (that is, the currently accepted idea that the time of fibrillation potential appearance is dependent upon the distance of the muscle from the lesion, with potentials appearing earlier when the distance between the neural lesion and the muscle is smaller)..$^{21,29,30}$ In multiple experiments, Langley and Kato found stronger fibrillations in proximal as compared to distal muscles. These early observations were not necessarily clinically applicable, as they had all been obtained by surgically exposing the denervated muscles and visually inspecting the surface. More reliable means of recording fibrillation potentials became available in the 1930 s and, thus, more intense investigation of this phenomenon became possible. ${ }^{21}$ In 1937, Brown ${ }^{1}$ unilaterally sectioned an unspecified number of cat sciatic nerves. He then allowed 4 to 27 days of denervation to pass before exposing the gastrocnemius muscles and examining them both visually for fibrillations and electrically for fibrillation potentials with concentric needle electrodes. From this work, Brown concluded that: i) fibrillation potentials "... are to be attributed to the activity of single muscle fibers"; and ii) "These observations are in agreement with those of Langley and Kato, who stated that fibrillation does not commence until the fifth day after nerve section." In 1944, Feinstein ${ }^{18}$ reported a large number of human nerve injury cases related to the Second World War. They noted that"... in no case of proved axonal interruption have we failed to find repetitive action potentials indicative of fibrillation." In the same article, they reported that, in a series of 25 patients undergoing laminectomies for prolapsed disks, the earliest onset of electrically detectable sacrospinalis muscle fibrillation potentials occurred 12 days after surgery. Publications by Feinstein et al.(1945) ${ }^{27}$ and Denny-Brown and Pennybacker $(1938)^{2}$ became the cited basis upon which the timing of onset of fibrillation potentials was determined. In essence, these 2 articles, particularly the former, defined the accepted wisdom as typified by Jasper and Ballem in $1949^{31}$ : "Suffice it to repeat here that fibrillation... was found most active two to four weeks following nerve lesion." The often cited Eaton and Lambert paper ${ }^{32}$ "Electromyography and Electric Stimulation of Nerves in Diseases of Motor Unit" from 1957 summarized fibrillation potential timing as: "They are observed regularly in denervated muscle, beginning 2 to 3 weeks after interruption of the axon and persisting for a variable time up to many years thereafter."

To determine the length dependent nature of the onset of fibrillation potentials, Luco and Eyzaguirre ${ }^{29}$ experimentally sectioned the sciatic nerve of two groups of animals: 1) the sciatic nerves of one group were sectioned high in the pelvis, while 2) the sciatic nerves of the animals in the second group were sectioned at the nerve twig to the tenuissimus muscle; the result was that there was a difference in residual nerve length of 25-35 mm between the two groups. In the former group, fibrillation potentials were first detectable at $140 \mathrm{~h}$, whereas in the latter, fibrillation potentials were present in all by $120 \mathrm{~h}$. From this work, the investigators concluded: "...if the cut portion of a nerve is short the above phenomena [fibrillation potentials] appear earlier than when a greater length of nerve is left to degenerate." Salafsky et al. ${ }^{30}$ published similar findings in 1968 based on experiments designed to determine if there was a difference between the onset of fibrillation potentials in fast versus slow twitch muscle and to investigate length dependency of onset. As with Luco and Eyzaguirre, $^{29}$ they had demonstrated length dependency, however, only in muscles presumed to be slow twitch. The significance of this result is unclear, as neither the sampling interval nor the number of data points was detailed in the article. With the onset timing of fibrillation potentials issue thought to be relatively settled, scientific study in the late 1940s and early 1950 s shifted more toward study of the underlying mechanism of fibrillation potentials and their origin.

\section{Origins and consequences of muscle fibrillation}

Obviously, when a muscle is severed from its nerve, the muscle loses both the electrical stimulus the nerve provided as well as any chemical "neurotrophic" factors the nerve would have supplied. During the 1940's and 50's, Jarcho et al.33 expanded upon the "neurotrophic" hypothesis as put forward by Tower et al.34 in 1941, to experimentally localize the origin of fibrillation potentials to the end-plate. In $1957, \mathrm{Li}$ et al.35 experimentally determined "...membrane resting potentials of denervated muscle fibers tended to oscillate." This was ultimately an important finding, as membrane oscillation is one of the key concepts in the etiology of fibrillation potentials. Over the years, researchers have investigated losses of both electrophysiological input as well as potential neurotrophic factors as possible origins of fibrillation potentials and have provided numerous reports which ultimately demonstrate that it is mainly the loss of 


\section{News on skeletal muscle fibrillation analyses}

Eur J Trans Myol - Basic Appl Myol 2014; 24 (1): 41-54

electrophysiological stimulation that is responsible for the changes that occur in the sarcolemmal membrane and propagate the spontaneous fibrillations. In turn, the fibrillations themselves may affect cellular metabolism and muscle fiber size.

\section{Electrophysiological factors}

Numerous studies report that changes in resting membrane potential (rmp) occur within a few days of denervation, concomitant with the onset of fibrillation potentials. $^{36-40}$ Indeed, a $10-15 \mathrm{mV}$ depolarization of denervated muscle membrane has been rather consistently reported, ${ }^{21,41}$ and the onset of this change in rmp begins sooner when the denervation is closer to the muscle. ${ }^{42,43}$ Purves and Sakman ${ }^{44}$ reported in 1974 that spontaneous fibrillations arose from both rhythmically and irregularly discharging fibers. Their studies showed that the rhythmic fibrillations were associated with membrane potential oscillations while random discrete depolarizations were responsible for the fibrillation of the irregularly discharging fibers. Both types of event were inhibited when they removed sodium from the extracellular solution of the rat diaphragm preparations and by treatment with the sodium channel blocker tetrodotoxin (TTX). The researchers concluded, therefore, that both fibrillation types arose from localized changes in sodium conductance. This was supported by subsequent studies of Thesleff and Ward ${ }^{45}$ whose work on denervated extensor digitorum longus (EDL) muscle in rats also revealed that fibrillation potentials result from spontaneous biphasic membrane potential oscillations of increasing amplitude. They suggested that the hyperpolarizing phase of the oscillation relieves sodium channel inactivation so that more of these channels may open during the depolarizing phase of the oscillation, allowing the depolarizing phase to exceed threshold and produce an action potential. They pointed out that this mechanism, important for the initiation and continuation of fibrillation potentials, is similar to anode break excitation and suggested that the physiological calcium levels in denervated muscle may not be sufficient to stabilize muscle fiber membranes. Further, Smith and Thesleff ${ }^{46}$ used denervated mouse diaphragm muscle to demonstrate that spontaneous fibrillations were induced by changes in sodium conductance and could be abolished by disruption of the t-tubule system. Gage and co-workers described a persistent TTX-sensitive $\left(\mathrm{Na}^{+}\right)$current of similar amplitude in both innervated and denervated fibers and suggested that this could bring about fibrillation potentials in the denervated muscles (which have an increased input resistance) by producing greater depolarization in the denervated fibers. ${ }^{44=47}$ Pappone characterized sodium currents in innervated and denervated rat skeletal muscle. ${ }^{48}$ She noted that activation and inactivation of sodium currents were shifted to more negative potentials by $10 \mathrm{mV}$ and suggested that, because the resting membrane potential is depolarized relative to normal muscle, that the shift in activation could explain the fibrillations. These shifts in voltage dependence of both activation and inactivation, however, were not detected in rabbit muscle preparations. ${ }^{49}$ Instead, changes in channel inactivation were detected that would be expected to accelerate recovery from fast inactivation during the after potentials and, thereby, increase membrane excitability. Another proffered explanation for increases in sodium conductance in denervated muscle comes from $\left[{ }^{3} \mathrm{H}\right]$-ouabain binding studies which suggest that there is an increase in the number of $\mathrm{Na}^{+} / \mathrm{K}^{+}$ATPase molecules on the cell membrane of denervated cat muscle. ${ }^{50}$ Pappone also reported the discovery of a TTX-resistant sodium current. ${ }^{45=48}$ Expression of the TTX-resistant "cardiac-type" sodium channel has indeed been reported in denervated muscle $^{51,52}$ and Sekiguchi and colleagues have recently reported a TTX-resistant channel that is expressed in denervated muscle with the onset of fibrillation potentials. $^{53}$ This latter group used northern blot analysis to demonstrate that the TTX-resistant "cardiac-type" voltage-gated Nav1.5 sodium channel mRNA is up-regulated by day 2 post denervation in rat EDL and that its expression increases on day 3 with obvious decreased expression by day 6 . Immunohistochemistry using confocal microscopy revealed that Nav1.5 protein abundance continued to increase past day 3, with day 6 having the greatest signal. Indeed this time frame corresponds well with their measured onset of spontaneous fibrillations. Further, treatment of the animals with lidocaine (which has a greater affinity for TTX-resistant sodium channels than for the TTX-sensitive ones) decreased fibrillation activity without affecting compound muscle action potentials. This suggests that: 1) the lidocaine worked as a selective Nav1.5 blocker; and 2) Nav1.5 channels contribute to the production of TTX-resistant spontaneous fibrillations. It is not possible that these TTX-resistant channels are solely responsible for spontaneous fibrillation activity, however, because the membrane potential oscillations and random discrete depolarizations reported to be responsible (at least in part) for fibrillation $37=40,41=44,51=54$ are described as TTX-sensitive. ${ }^{43=46,52=55}$ Indeed, Prabhu and Oesterhave reported that the spontaneous fibrillation potentials of denervated rabbit muscle are TTXsensitive. $^{56}$

Changes in potassium currents and channel expression have also been reported to occur in skeletal muscle membrane soon after denervation. For example, decreases in potassium permeability have been reported to occur in denervated muscle ${ }^{57,58}$ and it is suggested that this could alter the sodium to potassium permeability ratio and contribute to the decline in membrane potential. ${ }^{59}$ Using patch clamp of membrane vesicles from 8-16 day denervated mouse EDL, 


\section{News on skeletal muscle fibrillation analyses}

Eur J Trans Myol - Basic Appl Myol 2014; 24 (1): 41-54

Escobar and co-workers ${ }^{60}$ reported the disappearance of an $81 \mathrm{pS}$ voltage-dependent $\mathrm{K}^{+}$channel from the denervated muscle and suggested this may contribute to membrane depolarization and reported decreases in $\mathrm{K}^{+}$permeability. ${ }^{61}$ However, they also reported the appearance of a $16 \mathrm{pS}$ channel in denervated muscle similar to SK channels. Indeed, also using patch clamp, Neelands and colleagues described a small conductance calcium-activated $\mathrm{K}^{+}(\mathrm{SK})$ current in denervated mouse skeletal muscle which was absent from innervated controls. ${ }^{62}$ Citing studies which show that a specific inhibitor of SK channels suppresses both hyper-excitability in denervated rat muscle ${ }^{63}$ and the myotonic runs in patients with myotonic muscular dystrophy, ${ }^{64}$ Neelands and collaborators suggested that this SK channel contributes to the hyper-excitability of denervated skeletal muscle. ${ }^{62}$ Because SK channels are found in T-tubules, these investigators further suggested that potassium ions may pass into and accumulate inside the tubules and produce a localized depolarization in an area on the membrane and, thus, contribute to the propagation of fibrillation action potentials.

Some studies also suggest that changes in cellular calcium levels/handling may be involved in modulation of fibrillation potentials. Indeed, it has been shown that post denervation, intracellular calcium levels increase in skeletal muscle ${ }^{65}$ and that the rate of calcium uptake into the sarcoplasmic reticulum (SR) declines; ${ }^{66}$ this could contribute to membrane depolarization. Accordingly, increases in extracellular calcium have been demonstrated to decrease the spontaneous activity in denervated muscle ${ }^{67}$ and studies treating denervated rats with dantrolene (an inhibitor of ryanodine receptor mediated calcium release channels on the SR) reveal inhibition of fibrillation activity. ${ }^{68}$ Brody monitored calcium binding over time in the microsomal fraction of control, tenotomized and also denervated guinea pig gastrocnemius muscles. It was reported that, in contrast to control and tenotomized muscle (which did not fibrillate), the calcium binding per unit weight of microsomal protein increased in the muscle of denervated animals in concert with development of fibrillations. ${ }^{69} \mathrm{He}$ suggested that the increased calcium uptake by the SR may mean that the release of calcium from the SR could be enhanced also. Therefore, an increase in excitation-contraction coupling could result from the enhanced ability of the SR to release calcium in denervated muscle and thus contribute to development of muscle fibrillations.

\section{Neurotrophic factors}

The adjective "neurotrophic" has been used to refer to chemicals that are released from neurons and have a regulatory effect on muscle physiology. Dissidence has arisen over whether use of the term should include nerve-muscle interactions dependent upon the neurotransmitter acetylcholine or be limited to use with nerve-muscle interactions which are not dependent upon excitatory impulse transmission. The possibility that alterations in the abundance and localization of acetylcholine receptors (AChR) on the membrane of denervated muscle could be involved with/or related to production of fibrillations has been considered by researchers and thus will be discussed briefly here. In 1937, Rosenblueth and Luco demonstrated that the muscarinic AChR blocking drug atropine had no effect on spontaneous fibrillations, suggesting that the acetylcholine (ACh) neurotransmitter was not involved in development of fibrillation potentials. ${ }^{70}$ However, Solandt and Magladery reported in 1940 that atropine could abolish fibrillations at relatively high doses, offering some support for the involvement of $\mathrm{ACh} .{ }^{15}$ Indeed, the early literature concerning the effects of drugs on fibrillations is often contradictory. ${ }^{27,71}$ In 1961, Josefsson and Thesleff showed that treatment of rabbit hind limb muscles with botulinum toxin (which inhibits ACh release from the nerve terminal) produced muscle fibrillations similar to those detected in denervated muscle. ${ }^{72}$ Indeed, numerous studies have shown that an increase in sensitivity to ACh shortly follows denervation, ${ }^{2,29,73-75}$ and this increased ACh sensitivity spreads from the motor end plate to the surface of the muscle fiber. ${ }^{73,76}$ The increased sensitivity is believed to be at least partially attributable to an increased synthesis of AChRs. ${ }^{77}$ It has been proposed that this increased sensitivity to ACh may indeed be the cause of muscle fibrillations. ${ }^{1}$ Interestingly, Brumback and co-workers found that in denervated rat muscle block of nicotinic AChRs enhanced fibrillations while block of muscarinic AChRs decreased fibrillation activity, suggesting that the specific effect of AChR stimulation on fibrillation varies with receptor subtype. ${ }^{78}$ In contradiction to the above findings with nicotinic AChRs, Bandi and colleagues worked with mouse myotube culture (obviously non-innervated) and showed that autocrine activation of nicotinic AChRs could induce increases in intracellular calcium and contraction of the myotubes. ${ }^{79}$ As expected, long term (days) continual stimulation of denervated rat diaphragm muscle resulted in a decline in sensitivity to ACh. ${ }^{55}$ However, Purves and Sakman showed that stimulation of muscle by fibrillation potentials does not lead to a significant decline in ACh sensitivity and suggested this is because the occurrence of fibrillations is intermittent. ${ }^{44}$ Although the effect may not be direct, the literature suggests that, indeed, ACh binding at neuromuscular junction receptors is somehow involved in modulation of fibrillation potentials in denervated muscle, but the mechanism is not fully understood.

Prior to 1972 , it was commonly believed by numerous researchers that neurotrophic factors, not related to excitatory impulse transmission, played a role in spontaneous fibrillation onset. However, in a series of 


\section{News on skeletal muscle fibrillation analyses}

Eur J Trans Myol - Basic Appl Myol 2014; 24 (1): 41-54

careful studies, Lomo and co-workers demonstrated that chronic electrical stimulation of denervated rat muscles prevented the development of sensitivity to $\mathrm{ACh}$ and further caused ACh-sensitivity to disappear from denervated muscles already ACh supersensitive. ${ }^{80,81}$ These studies strongly demonstrated that the muscle sensitivity to ACh is dependent on electrical input to the muscles and not on trophic factors contributed by the nerves. ${ }^{82}$

\section{Metabolic factors}

In 1945, Feinstein and associates demonstrated with animal models that the time to onset of fibrillation potentials is decreased by thyroidectomy while treatment with desiccated thyroid increases it. ${ }^{27}$ Further, they showed that small changes in temperature have a large direct effect on spontaneous fibrillation in denervated skeletal muscle. These data suggest that the level of spontaneous fibrillation activity is related to muscle metabolic rate; however, (as has been noted by numerous authors) it is often difficult to determine which changes contribute to development of fibrillation and which are a consequence of it. Indeed, denervated muscle exhibits decreased levels of glycogen $^{83-85}$ and changes in activity levels of numerous enzymes (e.g., decreased succinic dehydrogenase $^{86}$ and cytochrome oxidase activities ${ }^{87}$ with increased hexokinase activity ${ }^{88}$ ) and other factors involved in carbohydrate metabolism. ${ }^{83,84,86,88}$ In 1950 , Humoller and co-workers compared metabolic parameters in denervated and tenotomized muscle and found that glycogen levels dropped in both sets of samples and that in the tenotomized muscles this decline started before the commencement of the fibrillation they detected, suggesting that decreased glycogen levels may contribute to production of the spontaneous activity. ${ }^{83}$ This group also carefully assayed for inorganic phosphates, ATP and creatine phosphate to address inconsistencies in reports of these parameters in the (even) older literature. They reported increased phosphocreatine and drops in organic phosphates within 24 hrs; however, after 3 days, while the organic phosphate was still low, the phosphocreatine returned to near normal. ATP levels remained nearly constant for the first 5 days post denervation, but then began to slowly drop afterward. In 1954, Ware and co-workers suggested that the decreased rmp of denervated skeletal muscle could be brought about by the metabolic changes which deprived the tissue of adequate energy supplies and could disrupt the sodium pump which contributes to maintenance of the rmp. ${ }^{40}$ Subsequently, Corsi and colleagues severed the sciatic nerve of the hind limbs of dogs and measured both lactate oxidation and fibrillation potentials. ${ }^{89}$ They report that lactate oxidation levels and fibrillations were low and absent, respectively, for the first four days post denervation and were both most obvious at 10-20 days post procedure. The lactate oxidation decreased when fibrillation activity was no longer continuous. Interestingly, when they suppressed the fibrillation activity with either dihydroquinidine or procainamide, the lactate oxidation did not increase in the denervated muscles. The researchers suggest that the increase in lactate oxidation that occurs with denervation is caused by fibrillation. Izumi and associates measured fibrillation potentials in denervated rat muscle under both ischemic (blood flow interrupted) and hypoxic conditions. ${ }^{90}$ They reported that the fibrillations disappeared within minutes under the ischemic conditions and reappeared with blood flow, suggesting that blood may provide a factor important to fibrillation potential initiation. Although fibrillation potential amplitudes were not affected significantly by the low oxygen conditions, the fibrillation firing rate was positively correlated with both $\mathrm{PaO}_{2}$ and temperature. The group suggested that the rate of fibrillation potential initiation is proportional to the rate of aerobic metabolism.

\section{Cell Factors.}

One of the last result of myology research is the discovery in denervated muscle fiber of the surprising extent of satellite cells activation, proliferation (they indeed increase in number), fusion to myotubes and grow to regenerated muscle fibers that reach a third of those innervated even in aneural muscles, much more than that usually happens in muscle cultures (see for review in this issue Bruce M. Carlson, ${ }^{3}$ ). As it is well known from in vitro myogenesis, the new fibers soon or later start to contract and thus it is conceivably that they may contribute to fibrillation of denervated muscles, in particular of long term denervated muscles (see above and below for re-expression of embryonic genes, in particular of the myosin heavy chains genes). ${ }^{24,94-103}$

\section{Fibrillation Potentials and Atrophy}

In the early nineteenth century, it was suggested that the atrophy which occurs subsequent to denervation was a consequence of the excessive energy use incurred by the spontaneous fibrillations and so denervation-induced atrophy was referred to as "fatigue atrophy". ${ }^{85,104-109}$ However, in contrast to this idea, Fischer and collaborators (1939) showed that stimulation of denervated muscle slowed the loss of muscle (dry weight) and excitability, suggesting that the fibrillation activity might have a similar effect and, therefore, not cause but (in fact) inhibit muscle loss. ${ }^{105}$ The "fatigue atrophy" theory was indeed dealt a big blow in 1940 when researchers demonstrated that inhibiting fibrillation in denervated muscle with either quinidine or quinine did not stop atrophy. ${ }^{15,106}$ More recently, Herbison and co-workers (1983) demonstrated that electrical stimulation could actually reduce the degree of atrophy and the number of 


\section{News on skeletal muscle fibrillation analyses}

Eur J Trans Myol - Basic Appl Myol 2014; 24 (1): 41-54

fibrillations in denervated muscle. ${ }^{107}$ Accordingly, Lewis and colleagues (1988-89) showed that the rate of atrophy in the denervated muscle of rats and guinea pigs varies inversely with the percentage of fibers which exhibit fibrillation, ${ }^{108,109}$ suggesting that the fibrillations actually inhibit muscle atrophy to some degree. Studies also show that fiber type transitions known to occur in denervated rat muscle may stem from the differences in the fibrillatory properties of their muscles. ${ }^{10,111}$ Thus, it is commonly accepted that the stimulation from fibrillation potentials actually counteracts muscle loss to some extent.

\section{Diagnostic and prognostic values of fibrillations in peripheral nervous system injuries and disorders}

\section{Diagnostic value of fibrillations in peripheral nervous} system injuries and disorders

Clinically, the presence or absence of fibrillation potentials is used to help determine whether a nerve injury is either axonal or demyelinating in nature. Fibrillation potentials are easily detected by electromyography (EMG) and, in general, are first detected within days to $1-4$ weeks post denervation. ${ }^{17,23}$ The variable time of onset is attributed to nerve degeneration being length-dependent and, therefore, fibrillation potentials are expected to occur earlier in muscles closer to the site of nerve injury than in muscles further away. ${ }^{112,113}$ It is common in medical practice due to the intrinsic slowness of nerve recovery, however, to wait 3 to 4 weeks after an injury to do needle EMG studies to ensure that, should the injury be axonal, the electrical evidence for it is present. ${ }^{114}$ This time frame was not derived from randomized control trials or cohort trials, but from almost a century's worth of prospective animal based experimental studies, human case reports, and anecdotal experience. In general, fibrillation potential peak amplitudes are reported to range from approximately 100 to $>1000 \mu \mathrm{V}$; these also vary from muscle to muscle within a species ${ }^{16,115}$ and from species to species. $^{11,16,23}$

\section{Prognostic value of fibrillations in peripheral nervous system injuries}

Fibrillation potential persistence varies with species and with the distance of nerve lesion from the muscle. In animals, investigators have noted that the disappearance of fibrillations heralds the return of motor function after nerve injury and is useful to evaluate the timing of reinnervation. For example, the estimated time of disappearance of fibrillations in rat tongue is about 15 days after hypoglossal nerve crush. ${ }^{116}$ Previously, Muchnik and Kotsias studied characteristics of the reinnervation of rat skeletal muscle: they noted that fibrillation activity recorded extracellularly began to decrease on the twelfth day post denervation, but they suggested that reinnervation can take place independently of fibrillation activity as well as of extrasynaptic receptors. ${ }^{117}$ Herbison et al. studied the acetylcholine sensitivity and fibrillation potentials in electrically stimulated crush-denervated rat skeletal muscle and reported that the denervatedstimulated soleus muscles had fewer fibrillations after 5 to 15 days of electrical stimulation than their matched denervated controls. However, the ACh sensitivity throughout the experimental period and the fibrillatory activity from 20 to 30 days post-crush were similar in the denervated and the denervated-stimulated muscles. ${ }^{107}$ In dogs with recurrent laryngeal nerve (RLN) injuries, fibrillation potentials were found in laryngeal muscles from 1 to 3 months after injury, and reinnervation potentials appeared 3 to 6 months after incomplete injury. ${ }^{118}$ In human subjects, Jiang GL et al. reported that fibrillations appeared early after muscle denervation and remained strong for up to 69 months. ${ }^{11}$ The study, conducted on 173 patients with complete denervation of biceps brachii, also showed that mean FP amplitudes stayed at relatively high and stable levels during the first 4 months $(\sim 500 \mu \mathrm{V})$, decreased by 6 months after denervation and then decayed very slowly for the rest of the first year $(\sim 380 \mu \mathrm{V})$. After 1 year of denervation, the mean fibrillation amplitude was $262 \mu \mathrm{V} .^{11}$ These data are similar to those reported earlier by $\mathrm{Kraft}^{23}$ although in his study, Kraft states that when lesions are more than 1 year old, fibrillation potentials are unlikely to be more than $100 \mu \mathrm{V}$ in size. The reduction of fibrillation potential amplitudes correlates with size of type 1 fiber atrophy. Previous studies of human spinal cord injury have shown that spontaneous potentials emerge between 2 and 3 weeks post injury ${ }^{15,119}$, and are likely to persist indefinitely: $92 \%$ of subjects with chronic SCI demonstrated spontaneous activity in at least one muscle and $72 \%$ in more than one muscle. ${ }^{120}$ These data were confirmed by a recent study reporting that spontaneous activity (in the form of fibrillations and positive sharp waves) occurred in $100 \%$ of patients with complete thoracic or cervical level SCI of 3-32 years duration since injury. ${ }^{121}$ Assuming that tenotomized/immobilized muscles do not fibrillate, these observations suggest that, indeed, denervated myofibers occur in these patients. In fact, spontaneous fibrillation activity was detected in 3 or more of the 4 affected muscles tested. ${ }^{11}$ If independent analyses (e.g., expression of denervation molecular markers and presence of typical morphologic, morphometric features of denervated tissue) confirm this interpretation, the evidence could be a major push to revive fibrillation to investigate if sparse, but incremental denervation is among the mechanisms producing muscle atrophy in aging, i.e. sarcopenia. Indeed, it would be most interesting to confirm by longitudinal studies using SFEMG and Dynamic Echomyography (DyEM) that skeletal muscle of "normal seniors" experience incremental levels of subclinical denervation of muscle fibers. ${ }^{122-124}$ 


\section{News on skeletal muscle fibrillation analyses}

Eur J Trans Myol - Basic Appl Myol 2014; 24 (1): 41-54

\section{Usefulness of fibrillations for monitoring therapeutic interventions: human case reports and anecdotal experiences}

Wallerian degeneration is the process whereby nerves degenerate after axonal injury. It is characterized histologically by axonal blebbing and fragmentation into ovoids. ${ }^{125,126}$ The clinical correlation of Wallerian degeneration is generally taken to be failure of electrical conduction by the nerve distal to the site of injury and the onset of denervation potentials. ${ }^{112-}$ $114,124,125$ In turn, this information is used to prognosticate the time course and extent of recovery in response to therapeutic interventions.

An example is the case of a 47 year old man with a complete right median nerve lesion at the wrist, following an injury by cutting of the forearm. The complex trauma also caused a lesion of the radial artery, a total cross-section of the deep flexor tendon of the first toe and an injury to the flexor carpi radialis tendon. Three hours after the trauma, the patient underwent a surgical suture of artery, tendons and neurorrhaphy of the median nerve. After 10 days of healing, the patient was submitted to a neuromuscular electrical stimulation protocol 5 times a week, each session lasting 30 minutes, using these parameters: pulse duration $0.3 \mathrm{msec}$, current intensity < $25 \mathrm{mAmp}$ (according to pain sensation), stimulation frequency 50 $\mathrm{Hz}$ for 1 second and pause of 4 seconds. After 1 month of this training protocol, the patient reported an improvement of subjective sensitivity of the second and third fingers of the hand. At that time, we performed a dynamic echomyographic scan of the of the tenar muscles (TM) that showed initial muscular atrophy (innervated left hand $14.5 \mathrm{~mm}$ vs. denervated right hand $(13.3 \mathrm{~mm})$ and an increased echogenicity of the muscle, both accepted direct signs of denervation. To avoid muscular wasting, we decided to combine the neuromuscular electrical stimulation protocol with direct stimulation of the denervated tenar muscles, using the following parameters with the Demitalia SM1, Stimulator for Denervated Muscle of the Medical Technology,Turin (Italy): rectangular biphasic waves, pulse duration $150 \mathrm{msec}$ and pause of 2 seconds, applied every day for 30 minutes at $5 \mathrm{mAmp}$. Two months after the trauma, the needle EMG exam of the tenar muscle showed low level of spontaneous activity (fibrillations) and no voluntary recruitment of motor units. The nerve conduction studies showed no sensitive response of the median nerve with orthodromic stimulation of the first and third fingers.

After an additional 4 months, the EMG showed minor modifications of the spontaneous activity, further increase of subjective sensitivity of the second and third fingers of the hand, but absence of volitional activity of the tenar muscles. On the other hand, under dynamic echomyography, all the tenar muscles responded with clear contractions when electrically stimulated at $10 \mathrm{mAmps}$, a threshold far from pain sensation. It is worth mentioning that electrical stimulation achieved the goal of maintaining the left denervated tenar muscles $(14.0 \mathrm{~mm})$ almost at the thickness of the contralateral innervated left hand (14.4 $\mathrm{mm}$ ) and without any worsening during the period from 2 to 6 post-denervation months. Taken together, these results are clear evidence that combining fibrillation analyses with dynamic echomyography to monitor the denervation phase and to follow the rate of atrophy along with the effectiveness of the electrostimulation can help to develop a therapy that is finely tuned to specific patient's needs. ${ }^{120,130}$

\section{Possible role of Single Fiber EMG in the follow up of peripheral nerve injuries}

Single Fiber EMG (SFEMG) can be used to follow the course of reinnervation. The parameters of fiber density, mean jitter and percent blocking must each be followed and related to the type of injury to determine the stage of reinnervation. ${ }^{131}$ The amplitude of the action potential recorded with an SFEMG electrode from an average muscle fiber decreases to 200 microvolts $(\mu \mathrm{V})$ when the electrode is approximately $300 \mu \mathrm{m}$ from the muscle fiber. Thus, we can infer that action potentials greater than $200 \mu \mathrm{V}$ arise from muscle fibers within $300 \mu \mathrm{m}$ of the recording surface. By measuringmany sites within a muscle, the mean number of time-locked action potentials (APs) that have an amplitude greater than $200 \mu \mathrm{V}$ and rise time of less than 300 microseconds ( $\mu \mathrm{s})$ can be used to calculate the fiber density, which quantitates the local concentration of muscle fibers within the motor unit. This provides information that is analogous to type grouping in muscle biopsies. Also Bertorini et al. found that increased muscle-fiber density, delineated by SFEMG, was most prominent in diseases of ordinary denervation, namely motor neuron disorders and peripheral neuropathies, and it correlated with histochemical fiber type grouping. ${ }^{134}$ SFEMG was also used to evaluate chronic demyelinating neuropathies, where fiber density was significantly increased in patients with fibrillation as measured with the conventional needle EMG. The study showed that the SFEMG is mildly abnormal in many patients with demyelinating neuropathy and that this test is useful in detecting and quantitating axonal degeneration in demyelinating neuropathy. ${ }^{133}$

In 1974 Hakelius evaluated the pattern of reinnervation in 26 free autogenous muscle transplants, performed in 21 patients with facial palsy using EMG and SFEMG recordings. These researchers reported that SFEMG revealed that increased jitter and blockings occurred in the first months. The researchers further reported that action potential complexes became progressively more stable, but blockings remained detectable even after 12 months. ${ }^{135}$ Gray and colleagues used microstimulatory single-fiber electromyography to assess reinnervation 


\section{News on skeletal muscle fibrillation analyses}

Eur J Trans Myol - Basic Appl Myol 2014; 24 (1): 41-54

after motor nerve transplantation in rabbits. ${ }^{136}$ Considering these data, we suggest that muscle fiber density data along with the quantitative analysis of fibrillation activity using the SFEMG technique could be the best approach for assessment of the denervationreinnervation process in peripheral nerve injury.

Equally important are the results of Hofer et al. (2005) in the analyses of the electrophsiological properties of single muscle fibers in the permanently denervated muscle fibers of RISE subjects before and during h-b FES. ${ }^{137}$ Dynamic Echomyography will, indeed, have even higer impact if combibed with stimulation needle electromyography (SNMEG) to test the electrophysiological properties of single muscle fibers. Hofer et al. measured the muscle fiber conduction velocity (MFCV) and the shortest interstimulus interval (ISI) still eliciting a response to the second stimulus delivered to the fiber. MFCV recorded in the denervated patients before and after h-b FES therapy showed a significant increase in conduction velocity (fastest and mean CV) and reduced refractory periods (shortest ISI). This suggests that electrical stimulation training is effective to improve the electrical properties of the muscle fibre and SNEMG could serve as an additional measurement technique to specify the status of the denervated muscle.

\section{Fibrillation analyses: EMG and DyEM in the follow-up of denervation atrophy and h-b FES of denervated/reinnervating muscle}

As a result of information gathered from the Rise2Italy project, we have proposed and implemented a new protocol of quantitative ultrasonography (dubbed Dynamic Echomyography to stress the functional components of the analyses) for patients suffering with permanent or transitory Lower Motor Neuron denervation. ${ }^{130,131,138}$ The protocol have been used to evaluate changes in Tibialis Anterior, Deltoid, and Quadriceps muscles undergoing h-bFES by either neuromuscular stimulation or direct surface stimulation of the denervated/reinnervating muscles.

A case of a subject with a lesion of the right sciatic nerve was followed for 12 months, 6 months for a subject suffering left brachial palsy and 8 months for a Spinal Cord Injury ASIA A subject suffering incomplete Conus Cauda Syndrome, we analyzed the denervated/reinnervating muscles before and during $\mathrm{h}$ bFES training.r. When possible, we compared the affected muscles to the contralateral normal muscles using ultrasound to record: 1. Gross morphology and sonographic structure; 2. Tissue thickness; 3. Dynamic properties of voluntary and electrical stimulationinduced contraction-relaxation cycles; and 4. Shortterm and long-term modifications of arterial perfusion in response to volitional and electrical stimulationinduced contractions. Morphology and ultrasonographic structure of the denervated muscles changed during the period of h-bFES training from a pattern typical of muscle atrophy to a pattern which might be considered "normal" when detected in an older patient. Thickness improved significantly more in the middle than in the proximal and distal thirds of the denervated muscles, reaching approximately the same thickness of the contra lateral innervated muscle in a year. In all measurements, arterial perfusion of the denervated muscles showed a low resistance pattern with Doppler ultrasonography at rest, and a pulsed pattern after several months of h-b FES, more similar to the triphasic high-resistance pattern of the innervated muscles. Contraction-relaxation kinetics, measured by recording movements during electrical stimulation, showed an abnormal behavior in the denervated muscles., In agreement with many experimental animal models and clinical human observations, contraction-relaxation kinetics of the denervated muscle were significantly longer than in the normal muscle, particularly during relaxation was,. The very high current energy needed to activate the denervated muscles, according to the Vienna h-b FES strategy, is strong evidence that the explored muscles were still denervated. If they recovered volitional function, the energy of muscle activation went down to the values of motor point stimulation of innervated/reinnervated muscles.

All together, our observations confirm that h-b FES, EMG and DyEM and are useful for diagnosis and adjustment of treatments of denervated and reinnervating muscles. In the latter case, Dynamic Echomyography provides information on the muscles and/or muscle parts contracting under voluntary or electrical activation. We are confident that combining sound invasive "time zero" and "end-point" analyses (e.g., tissue biopsy, 2D or 3D Color CT macromorphometry with noninvasive, bed-side repeatable SMEMG (including fibrillation recording) and DyEM will allow researcher to address some of the following open issues: 1. Reliable evaluation of the extent of muscle denervation and reinnervation; 2. Reliable quantification of the progression of atrophy to degeneration in longstanding muscle denervation; 3 . Influence (positive or negative) of electrical stimulation on muscle reinnervation (in well-defined sub-groups of patients). In this manner, these techniques will contribute to the much-needed evidence-based approaches in Physical Medicine and Rehabilitation.

\section{Summary}

Fibrillation potentials of skeletal muscle are small spontaneous action potentials which are considered to be a hallmark response of skeletal muscle to denervation. They have been shown to arise from both oscillations in membrane potential and discrete membrane depolarizations resulting from changes in both sodium and potassium permeabilities. The fibrillations seem to prevent a more serious degree of 


\section{News on skeletal muscle fibrillation analyses}

Eur J Trans Myol - Basic Appl Myol 2014; 24 (1): 41-54

initial atrophy in denervated muscle and are sometimes used to assess the degree of neural injury and reinnervation that have occurred. It is suggested that these may also be useful to assess the degree of atrophy that exists. For patients with peripheral nerve injury, therapeutic interventions such as electrical muscle stimulation may be helpful in preserving the contractility and extensibility of denervated muscle tissue and in retarding muscle atrophy. There is no doubt that the literature highlights controversy over the benefits of electrical stimulation for peripheral neuropathies, but the overall goal of all is to keep muscle tissue healthier and viable until reinnervation is established. Monitoring fibrillations may be useful to verify that electrical stimulation is not detrimental to terminal nerve growth (i.e., the stimulus parameters are wisely selected and the amplitude is applied at a level that does not fatigue the regenerating nerve or stress the healing tissue). It is obvious from the paucity of recent literature that research in this area has declined over the years. This is likely a consequence of the decrease in funding available for research and the fact that the fibrillations do not appear to cause serious health issues. Nonetheless, further exploration of fibrillations as diagnostic tools is merited, in particular if combined with Dynamic Echomyography, an Ultra Sound muscle approach we designed and developed to explore denervated and reinnervating muscles.

\section{Acknowledgements}

The authors wish to thank the editor and editorial board of The European Journal of Translational Myology for the opportunity to write this review paper. It is an honor.

In memory of Herwig Thoma, without his creativity and his Vienna FES Meetings, neither the ViennaPadua collaborations nor the Padua Muscle Days would have existed, nothing to say, the European Journal of Translational Myology.

\section{Corresponding Author}

Andrea Marcante, CIR-Myo, Physiatry Unit, Department of Neuroscience, University of Padova, Italy and UOC Spinal Cord diseases - Department of Neurorehabilitation, Fondazione Ospedale San Camillo - I.R.C.C.S., Via Alberoni, 70 - 30126 Venezia-Lido, Italy

Email: andrea.marcante@studenti.unipd.it

\section{List of Abbreviations}

Ach, acetylcholine, AChR, acetylcholine receptor, AP, action potential, DyEM, Dynamic EchoMyography; EDL, extensor digitorum longus, EMG, electromyography, h-b FES, home-based functional electrical stimulation, ISI, inter-stimulus interval, MFCV, muscle fiber conduction velocity, NMES, neuromuscular electrical stimulation, rmp, resting membrane potential, SCI, spinal cord injury, SFEMG,
Single Fiber electromyography, SNMEG, Stimulation needle electromyography, SK, small conductance calcium-activated potassium channel (or its current), SR, sarcoplasmic reticulum, TTX, tetrodotoxin

\section{References}

1. Brown GL. The actions of acetylcholine on denervated mammalian and frog's muscle. J Physiol 1937;89:438-61

2. Denny-Brown D, Pennybacker JB. Fibrillation and fasciculation in voluntary muscle. Brain 1938;61:311-34.

3. Langley JN, Kato T. The physiological action of physostigmine and its actions on denervated skeletal muscle. J Physiol 1915;49:410-31.

4. Desmedt JE, Borenstein S. Relationship of spontaneous fibrillation potentials to muscle fibre segmentation in human muscular dystrophy. Nature 1975;258:531-4.

5. Henriksson K-G, Stalberg E. The terminal innervation pattern in polymyositis: a histochemical and SFEMG study. Muscle Nerve 1978;1:3-13.

6. Streib EW, Wilbourn AJ, Mitsumoto H. Spontaneous electrical muscle fiber activity in polymyositis and dermatomyositis. Muscle Nerve 1979; 2:14-18.

7. Behnia M, Kelly JJ. Role of electromyography in amyotrophic lateral sclerosis. Muscle Nerve 1991;14:1236-41.

8. Carlson BM. The biology of long-term denervated skeletal muscle. Eur J Trans Myol Basic Appl Myol 2014;24:5-11.

9. Carraro U, Rossini K, Mayr W, Kern H. Muscle fiber regeneration in human permanent lower motoneuron denervation: relevance to safety and effectiveness of FES-training, which induces muscle recovery in SCI subjects. Artif Organs 2005;29:187-91.

10. Aisen ML, Brown W, Rubin M. Electrophysiologicl changes in lumbar spinal cord after cervical cord injury. Neurology 1992; 42:623-26.

11. Jiang G-L, Zhang L-Y, Shen L-Y, Xu J-G, Gu Y-D. Fibrillation potential amplitude to quantitatively assess denervation muscle atrophy. Neuromusc Disorders 2000;10:85-91.

12. Nyboer VJ, Johnson HE. Electromyographic findings in lower extremities of patients with traumatic quadriplegia. Arch Phys Med Rehabil 1971;52:256-59.

13. Riley DA, Burns AS, Carrion-Jones M, Dillingham TR. Electrophysiological dysfunction in the peripheral nervous system following spinal cord injury. Am Acad Phys Med Rehabil 2011;3:419-25. 


\section{News on skeletal muscle fibrillation analyses}

Eur J Trans Myol - Basic Appl Myol 2014; 24 (1): 41-54

14. Rosen JS, Lerner IM, Rosenthal AM. Electromyography in spinal cord injury. Arch Phys Med Rehabil 1969; 50:271-73.

15. Taylor RG, Kewalramani LS, Fowler WM, Jr. Electromyographic findings in lower extremities of patients with high spinal cord injury. Arch Phys Med Rehabil 1974;55:16-23.

16. Burns AS, Lemay MA, Tessler A. Abnormal spontaneous potentials in distal muscles in animal models of spinal cord injury. Muscle Nerve 2005;31:46-51.

17. Solandt DY, Magladery JW. The realation of atrophy to fibrillation in denervated muscle. Brain 1940;63:255-63.

18. Weddel G, Feinstein B, Pattle RE. The electrical activity of voluntary muscle in man under normal and pathological conditions. Brain 1944;67:178-257.

19. Dumitru D, King JC. Fibrillation potential amplitude after denervation. Am J Phys Med Rehabil 1998;77:483-89.

20. Robinson LR. Traumatic injury to peripheral nerves. Muscle Nerve 2000;23:863-73.

21. Willmott AD, White C, Dukelow SP. Fibrillation potential onset in peripheral nerve injury. Muscle Nerve 2012; 46:332-40.

22. Eccles JC. Changes in muscle produced by nerve degeneration. Med J Australia 1941;1:573-575.

23. Kraft GH. Fibrillation potential amplitude and muscle atrophy following peripheral nerve injury. Muscle Nerve 1990;13:814-21.

24. Guo X, Greene K, Akanda N, Smith A, Stancescu M, Lambert S, Vandenburgh H, Hickman J. In vitro Differentiation of Functional Human Skeletal Myotubes in a Defined System. Biomater Sci 2014;2:131-8.

25. Schiff M. Direct observations of denervated muscle. Arch Physiol Heilk 1851;10:579-93.

26. Langley JN, Kato T. The physiological action of physostigmine and its action on denervated skeletal muscle. J Physiol 1915; 49:410-31.

27. Feinstein B, Pattle RE, Weddell G. Metabolic factors affecting fibrillation in denervated muscle. J Neurol Neurosurg Psychiatry1945; 8: $1-11$.

28. Langley JN, Hashimoto M. Observations on the atrophy of denervated muscle. J Physiol 1918;52:15-69.

29. Luco JV, Eyzaguirre C. Fibrillation and hypersensitivity to ACh in denervated muscle: effect of length of degenerating nerve fibers. J Neurophysiol 1955;18:65-73.

30. Salafsky B, Bell J, Prewitt MA. Development of fibrillation potentials in denervated fast and slow skeletal muscle. Am J Physiol 1968;215:637-43.
31. Jasper H, Ballem G. Unipolar electromyograms of normal and denervated human muscle. J Neurophysiol 1949;12:231-44.

32. Eaton LM, Lambert EH. Electromyography and electric stimulation of nerves in diseases of motor unit; observations on myasthenic syndrome associated with malignant tumors. JAMA 1957;163:1117-24.

33. Jarcho LW, Berman B, Dowben RM, Lilienthal JL. Site of origin and velocity of conduction of fibrillary potentials in denervated skeletal muscle. Am J Physiol 1954;178:129-34.

34. Tower SS, Bodian D, Howe H. Fibrillation in skeletal muscle in relation to denervation and to inactivation without denervation. J. Neurophysiol 1941;4:388-401.

35. Li CL, Shy GM, Wells J. Some properties of mammalian skeletal muscle fibers with particular reference to fibrillation potentials. J Physiol 1957;135:522-35.

36. Albuquerque EX, Thesleff S. A comparative study of membrane properties of innervated and chronically denervated fast and slow skeletal muscles of the rat. Acta Physiol Scand 1968;73:471-80

37. Germinario E, Esposito A, Megighian A, Midrio M, Biral D, Betto R, Danieli-Betto D. Early changes of type $2 B$ fibers after denervation of rat EDL skeletal muscle. J Appl Physiol 2002;92:2045-52.

38. Lewis DM. The effect of denervation on the mechanical and electrical responses of fast and slow mammalian twitch muscle. J Physiol (Lond) 1972;222:51-75.

39. Midrio M, Daniele-Betto D, Megighian A, Betto R. Early effects of denervation on sarcoplasmic reticulum properties of slow twitch rat muscle fibres. Pflugers Arch 1997;434:398-405.

40. Ware F JR, Bennett AL, McIntyre AR. Membrane resting potential of denervated mammalian skeletal muscle measured in vivo. Potentials Denerv Muscle 1954;177:115-8.

41. Midrio M. The denervated muscle: facts and hypotheses. A historical review. Eur J Appl Physiol 2006;98:1-21.

42. Albuquerque EX, Schuh FT, Kaufman FC. Early membrane depolarization of the fast mammalian muscle after denervation. Pfluger Arch 1971;328:36-50.

43. Locke S, Solomon HC. Relation of resting potential of rat gastrocnemius and soleus muscles to innervation, activity and the $\mathrm{Na}-\mathrm{K}$ pump. J Exp Zool 1967;166:377-86.

44. Purves D, Sakmann B. Membraneproperties underlying spontaneous activity of denervated muscle fibres. J Physiol 1974;239:125-53. 


\section{News on skeletal muscle fibrillation analyses}

Eur J Trans Myol - Basic Appl Myol 2014; 24 (1): 41-54

45. Thesleff S, Ward MR. Studies on the mechanism of fibrillation potentials in denervated muscle. J Physiol 1975;244:313-23.

46. Smith JW, Thesleff S. Spontaneous activity in denervated mouse diaphragm muscle. J. Physiol. 1976;257:171-86.

47. Gage PW, Lamb GD, Wakefield BT. Transient and persistent sodium currents in normal and

48. Pappone PA. Voltage-clamp experiments in normal and denervated mammalian skeletal muscle fibres. J. Physiol. 1980;306:377-410.

49. Kirsch GE, Anderson MF. Sodium channel kinetics in normal and denervated rabbit muscle membrane. Muscle Nerve 1986;9:738-47.

50. Sharma VK, Dasgupta SR, Banerjee SP. [3H]Ouabain binding to denervated and innervated skeletal muscle. Euro J Pharmacol 1977;43:2736.

51. Lupa MT, Krzemien DM, Schaller KL, Caldwell JH. Expression and distribution of sodium channels in short- and long-term denervated rodent skeletal muscles. J Physiol 1995;483:109-18.

52. Rogart RB, Cribbs LL, Muglia LK, Kephart DD, Kaiser MW. Molecular cloning of a putative tetrodotoxin-resistant rat heart $\mathrm{Na}+$ channel isoform. Proc Natl Acad Sci 1989; 86:8170-4.

53. Sekiguchi K, Kanda F, Mitsui S, Kohara N, Chihara K. Fibrillation potentials of denervated rat skeletal muscle are associated with expression of cardiac-type voltage-gated sodium channel isoform Nav 1.5. ClinNeurophys 2012;123:1650-5.

54. Li C-L. Mechanism of fibrillation potentials in denervated mammalian skeletal muscle. Science 1960;132:1889-90.

55. Purves D, Sakmann B. The effect of contractile activity on fibrillation and extrajunctional acetylcholine-sensitivity in rat muscle maintained in organ culture. J Physiol 1974a;237:157-82.

56. Prabhu VG, Oester YT. Abolition by tetrodotoxin of the spontaneous fibrillation potentials of denervated skeletal muscle of rabbit. An in vivo comparative electromyographic study. Arch Int Pharmacodyn Ther 1974;208:255-63.

57. Kernan RP, McCharty I. Effects of denervation on $42 \mathrm{~K}$ influx and membrane potential of rat soleus muscles measured in vivo. J Physiol (Lond) 1972; 226:62-3.

58. Klaus W, Lullman H, Muscholl E. Der kaliumefflux beim normalen und denervierten rattenzwerchfell. Pfluger Arch GesPhysiol 1960; 271:761.

59. Thesleff S. Physiological effects of denervation of muscle. Ann N Y Acad Sci 1976;36:89-104.
60. Escobar ALM, Schinder AF, Biali FI et al. Potassium channels from normal and denervated mouse skeletal muscle fibers. Muscle Nerve 1993;16:579-86.

61. Kotsias BA, Venosa RA. Role of sodium and potassium permeabilities in the depolarization of the denervated rat muscle fibers. J Physiol (Lond) 1987;392:301-13.

62. Neelands TR, Herson PS, Jacobson D et al. Small-conductance calcium-activated potassium currents in mouse hyperexcitable denervated skeletal muscle. J Physiol. 2001;536:397-407.

63. Vergara C, Ramirez B, Behrens MI. Colchicine alters apamin receptors, electrical activity and skeletal muscle relaxation. Muscle Nerve 1993; 16:935-940.

64. Behrens MI, Jalil P, Serani A, et al. Possible role of apamin-sensitive $\mathrm{K}+$ channels in myotonic dystrophy. Muscle Nerve 1994;17:1264-70.

65. Hines HM, Knowlton GC. Changes in the skeletal muscle of the rat following denervation. Am J Physiol 1933;104:379-91.

66. Streter FA. Effect of denervation on fragmented sarcoplasmic reticulum of white and, red muscle. Exp Neurol 1970;29:52-64.

67. Hnik P, Skorpil V. Fibrillation activity in denervated muscle. In Gutmann $\mathrm{E}$,ed. The Denervated Muscle. Prague: Publishing House of Czechoslovak Academy of Sciences 1962. pp 135-150.

68. Izumi S-I, Tsubahara A, Chino N, Mineo K. Effects of dantrolene sodium on fibrillation potentials in denervated rat muscles. Muscle Nerve 1998;21:1797-9.

69. Brody IA. Relaxing factor in denervated muscle: a possible explanation of fibrillations. Am J Physiol 1966;211:1277-80.

70. Rosenblueth A, Luco JV. A study of denervated mammalian skeletal muscle. Am J Physiol 1937;120:781-797.

71. Guth L. "Trophic" influences of nerve on muscle. Physiol Rev 1968;48:645-87.

72. Josefsson J-O, Thesleff S. Electromyographic findings in experimental botulinum intoxication. Acta Physiol Scand 1961;51:163-8.

73. Axelsson J, Thesleff S. A study of supersensitivity in denervated mammalian skeletal muscle. J Physiol (Lond) 1959;149:178-93.

74. Heathcote RD. Acetylcholine-gated and chloride conductance channel expression in rat mucle membrane. J Physiol 1989; 414:473-97.

75. Miledi R. Junctional and extrajunctional ACh receptors in skeletal muscle fibers. J Physiol 1960;151:24-30. 


\section{News on skeletal muscle fibrillation analyses}

Eur J Trans Myol - Basic Appl Myol 2014; 24 (1): 41-54

76. Buller AJ, Eccles JC, Eccles RM. Differentiation of fast and slow muscles in the cat hind limb. J Physiol. 1960 Feb;150:399-416.

77. Fambrough DM. Control of acetylcholine receptors in skeletal muscle. Physiol Rev 1979; 59:165-227.

78. Brumback RA, Bertorini TE, Engel WK et al. The effect of pharmacologic acetylcholine receptor on fibrillation and myotonia in rat skeletal muscle. Arch Neurol 1978;35:8-10.

79. Bandi E, Bernareggi A, Grandolfo $M$ et al. Autocrine activation of nicotinic acetylcholine receptors contributes to $\mathrm{Ca} 2+$ spikes in mouse myotubes during myogenesis. J Physiol 2005; 568:171-80.

80. Lomo T, Rosenthal J. Control of ACh sensitivity by muscle activity in the rat. $\mathbf{J}$ Physiol 1972; 221:493-513.

81. Westgaard, RH, Influence of activity on the passive electrical properties of denervated soleus muscle fibres in the rat. J Physiol (Lond) 1975; 251:683-97.

82. Lomo T. The response of denervated muscle to long-term stimulation (1985, revisited here in 2014). Eur J Trans Myol - Basic Appl Myol 2014 24:13-19.

83 Humoller FL, Griswold B, McIntyre AR. Comparative chemical studies in skeletal muscle following neurotomy and tenotomy. Muscle Atrophy 1950;161:406-12.

84. Knowlton GC; Hines HM. The respiratory metabolism of atrophic muscle. Am J Physiol 1934;109:200-8.

85. Levine R, Hechter O, Soskin S. Biochemical characteristics of denervated skeletal muscle at rest and after direct stimulation. Am J Physiol 1941;132:336-45.

86. Humoller FL, Griswold B, McIntyre AR. Effect of neurotomy on succinic dehydrogenase activity of muscle. Am J Physiol 1951;164:7427.

87. Humoller FL, Hatch D, McIntyre AR. Cytochrome oxidase activity in muscle following neurotomy. Am J Physiol 1952;170:371-4.

88. Humoller FL, Hatch D, McIntyre AR. Effect of neurotomy on hexokinase and phosphorylase activities of rat muscle. Am $\mathrm{J}$ Physiol 1951;167:656-64.

89. Corsi A, Midrio M, Granata AL, Corgnati A, Wolf D. Lactate oxidation by skeletal muscle in vivo after denervation. Am J Physiol 1972;223:219-22.

90. Izumi S-I, Tsubahara A, Chino N. Relationship between hypoxemia and fibrillation potential firing rate in denervated muscle. Muscle Nerve $1999 ; 22: 933-6$
91. Langley JN. Observations on denervated muscle. J Physiol 1916;50:335-44.

92. Levine R, Hechter O, Soskin S. Biochemical characteristics of denervated skeletal muscle, at rest and after direct stimulation. Biochem Denerv Muscle 1940:336-45.

93. Hines HM, Knowlton GC. The role of the nervous system in the regulation of the glycogen metabolism of skeletal muscle. Am J Physiol 1935;111:243-49.

94. Carraro U, Morale D, Mussini I, et al. Chronic denervation of rat hemidiaphragm: maintenance of fiber heterogeneity with associated increasing uniformity of myosin isoforms. J Cell Biol. 1985;100:161-74.

95. Mussini I, Favaro G, Carraro U. Maturation, dystrophic changes and the continuous production of fibers in skeletal muscle regenerating in the absence of nerve. $\mathbf{J}$ Neuropathol Exp Neurol 1987;46:315-31.

96. Jakubiec-Puka A, Kordowska J, Catani C, Carraro U. Myosin heavy chain isoform composition in striated muscle after denervation and self-reinnervation. Eur $\mathrm{J}$ Biochem. 1990;193:623-8

97. Midrio M, Danieli-Betto D, Megighian A, Velussi C, Catani C, Carraro U. Slow-to-fast transformation of denervated soleus muscle of the rat, in the presence of an antifibrillatory drug. Pflugers Arch 1992;420:446-50.

98. Jakubiec-Puka A, Catani C, Carraro U. Myosin heavy-chain composition in striated muscle after tenotomy. Biochem J 1992;282:237-42.

99. Cantini M, Massimino ML, Catani C, Rizzuto R, Brini M, Carraro U. Gene transfer into satellite cell from regenerating muscle: bupivacaine allows beta-Gal transfection and expression in vitro and in vivo. In Vitro Cell Dev Biol Anim 1994;30A:131-3.

100. Cantini M, Carraro U. Macrophage-released factor stimulates selectively myogenic cells in primary muscle culture. J Neuropathol Exp Neurol 1995;54:121-8.

101. Midrio M, Danieli-Betto D, Esposito A, et al. Lack of type 1 and type 2A myosin heavy chain isoforms in rat slow muscle regenerating during chronic nerve block. Muscle Nerve. 1998;21:226-32.

102. Podhorska-Okolow M, Sandri M, Zampieri S, et al. Apoptosis of myofibres and satellite cells: exercise-induced damage in skeletal muscle of the mouse. Neuropathol Appl Neurobiol. 1998;24:518-31.

103. Squecco R, Carraro U, Kern H, et al. A subpopulation of rat muscle fibers maintains an assessable excitation-contraction coupling mechanism after long-standing denervation 


\section{News on skeletal muscle fibrillation analyses}

Eur J Trans Myol - Basic Appl Myol 2014; 24 (1): 41-54

despite lost contractility. J Neuropathol Exp Neurol 2009;68:1256-68.

104. Tower SS. Persistence of fibrillation in denervated skeletal muscle and its nonoccurrence in muscle after tenotomy. Arch Neurol Psych 1939;42:219-23.

105. Fischer E. The effect of faradic and galvanic stimulation upon the course of atrophy in denervated skeletal mucles. Am J Physiol 1939;127:605-18.

106. Ravin A. Effects of quinine on mammalian skeletal muscle. Am J Physiol 1940;131:228-39.

107. Herbison GJ, Jaweed MM, Ditunno JF Jr. Acetylcholine sensitivity and fibrillation potentials in electrically stimulated crushdenervated rat skeletal muscle. Arch Phys Med Rehabil 1983;64:217-20.

108. Al-Amood WS, Lewis DM. A comparison of the effects of denervation on the mechanical properties of rat and guinea-pig skeletal muscle. J Physiol 1989;414:1-16.

109. Lewis DM, Robinson AJ, Tufft NR. Fibrillation in the denervated skeletal muscle of the anaesthetized rat and guinea-pig. J Physiol (Lond) 1988;403:69.

110. Midrio M, Daniele-Betto D, Megighian A, et al. Slow-to-fast transformation of denervated soleus muscle of the rat, in the presence of an antifibrillatory drug. Pflügers Arch 1992;420:446-50.

111. Windisch A, Gundersen K, Szaboles MJ, et al. Fast to slow transformation of denervated and electrically stimulated rat muscle. J Physiol 1998;510:623-32.

112. Dumitru D, Zwarts M. Needle electromyography. In: Dumitru D, Amato AA, Zwarts M, editors. Electrodiagnostic Medicine.Philadelphia: Hanley and Belfus; 2001. pp 257-291.

113. Brown WF, Bolton CF. Pathophysiology of conduction in peripheral neuropathies. In: Neuromusular function and disease. Boston: Butterworth-Heinemann; 1993. pp 56-95.

114. Robinson LR. Traumatic injury to peripheral nerves. Muscle Nerve 2000;23:863-73.

115. Carter JG, Sokoll MD, Gergis SD. Effect of spinal cord transection on neuromuscular function in the rat. Anesthesiology 1981;55:542-46.

116. Heaton JT, Kobler JB. Use of muscle fibrillation for tracking nerve regeneration. Muscle Nerve 2005;3:235-41.

117. Muchnik S, Kotsias BA. Characteristics of reinnervation of skeletal muscle in the rat. Acta Physiol Lat Am 1976;26:481-93.

118. $\mathrm{Xu} \mathrm{W,} \mathrm{Han} \mathrm{D,} \mathrm{Hu} \mathrm{H,} \mathrm{Fan} \mathrm{E} \mathrm{Ann.}$ Characteristics of experimental recurrent laryngeal nerve surgical injury in dogs. Otol Rhinol Laryngol. 2009;118:575-80.

119. Spielholz NI, Sell GH, Goodgold J, Rusk HA, Greens SK. Electrophysiological studies in patients with spinal cord lesions. Arch Phys Med Rehabil 1972;53:558 -62

120. Kirshblum, S. Lim, S. Garstang, S. Millis Electrodiagnostic changes of the lower limbs in subjects with chronic complete cervical spinal cord injury Arch Phys Med Rehabil. 2001;82:604-7

121. Riley DA, Burns AS, Carrion-Jones M, Dillingham TR. Electrophysiological dysfunction in the peripheral nervous system following spinal cord injury. PM R. 2011;3:419-25.

122. Mosole S, Rossini K, Kern H, et al. Significant increase of Vastus lateralis reinnervation in 70year sportsmen with a lifelong history of highlevel exercise. Eur J Trans Myol/Basic Appl Myol 2013; 23:117-22.

123. Mosole S, Carraro U, Kern H, et al. Long term high-level exercise promotes muscle reinnervation with age. J Neuropathol Exp Neurol 2014;73, in press.

124. Editors. In this Issue. J Neuropathol Exp Neurol 2014; $73: 103$. doi: 10.1097/NEN.0000000000000041.

125. Fenrich K, Gordon T. Canadian Association of Neuroscience review: axonal regeneration in the peripheral and central nervous systems-current issues and advances. Can $\mathbf{J}$ Neurol Sci 2004;31:142-56.

126. Koeppen AH. Wallerian degeneration: history and clinical significance. J Neurol Sci 2004; 220: $115-17$.

127. Preston DC, Shapiro BE. Clinicalelectrophysiologic correlations: overview and common patterns. In: Electromyography and neuromuscular disorders. Philadelphia: Elsevier; 2005. pp 233-251.

128. Kimura J. Anatomy and physiology of the peripheral nerve. In: Electrodiagnosis in disease of nerve and muscle. New York: Oxford University Press; 2001. pp 63-91.

129. Marcante A, Zanato R, Ferrero M, et al. Recovery of Tetanic Contractility of Denervated Muscle: A Step Toward a Walking Aid for Foot Drop. Biomed Tech (Berl). 2013 Sep 7. pii: /j/bmte.2013.58.issue-s1-A/bmt-20134016/bmt-2013-4016.xml. doi: 10.1515/bmt2013-4016. [Epub ahead of print]

130. Zanato R, Stramare R, Boato N, et al. Dynamic Echomyography Shows That FES in Peripheral Denervation does not Hamper Muscle Reinnervation. Biomed Tech (Berl). 2013 Sep 7. pii: /j/bmte.2013.58.issue-s1-A/bmt-2013- 


\section{News on skeletal muscle fibrillation analyses}

Eur J Trans Myol - Basic Appl Myol 2014; 24 (1): 41-54

4034/bmt-2013-4034.xml. doi: 10.1515/bmt2013-4034. [Epub ahead of print].

131. Wiechers D. Single fiber EMG evaluation in denervation and reinnervation. Muscle Nerve. 1990 Sep;13:829-32.

132. Harris AJ, Duxson MJ, Butler JE et al. Muscle fiber and motor unit behavior in the longest human skeletal muscle. J Neurosci 2005;25:8528-33.

133. Oh SJ. The single-fiber EMG in chronic demyelinating neuropathy. Muscle Nerve. 1989:12:371-7.

134. Bertorini TE, Stalberg E, Yuson CP, Engel WK. Single-fiber electromyography in neuromuscular disorders: correlation of muscle histochemistry, single-fiber electromyography, and clinical findings. Muscle Nerve. $1994 ; 17: 345-53$
135. Hakelius L, Stälberg E. Electromyographical Studies of Free Autogenous Muscle Transplants in Man. Scand J Plast Reconstr Surg. 1974;8:211-19

136. Gray WP, Keohane C, Kirwan WO. Motor nerve transplantation. J Neurosurg 1997;87:61524.

137. Hofer C, Forstener C, Moedlin M, et al. In vivo assessment of conduction velocity and refractory period of denervatd muscle fibers. Artif Organs 2005;29:436-39.

138. Zanato R, Martino L, Stramare R. Functional Echomyography of the human denervated muscle: first results [Ecomiografia funzionale del muscolo umano denervato: primi risultati]. Eur J Trans Myol 2011;21: 3-29.

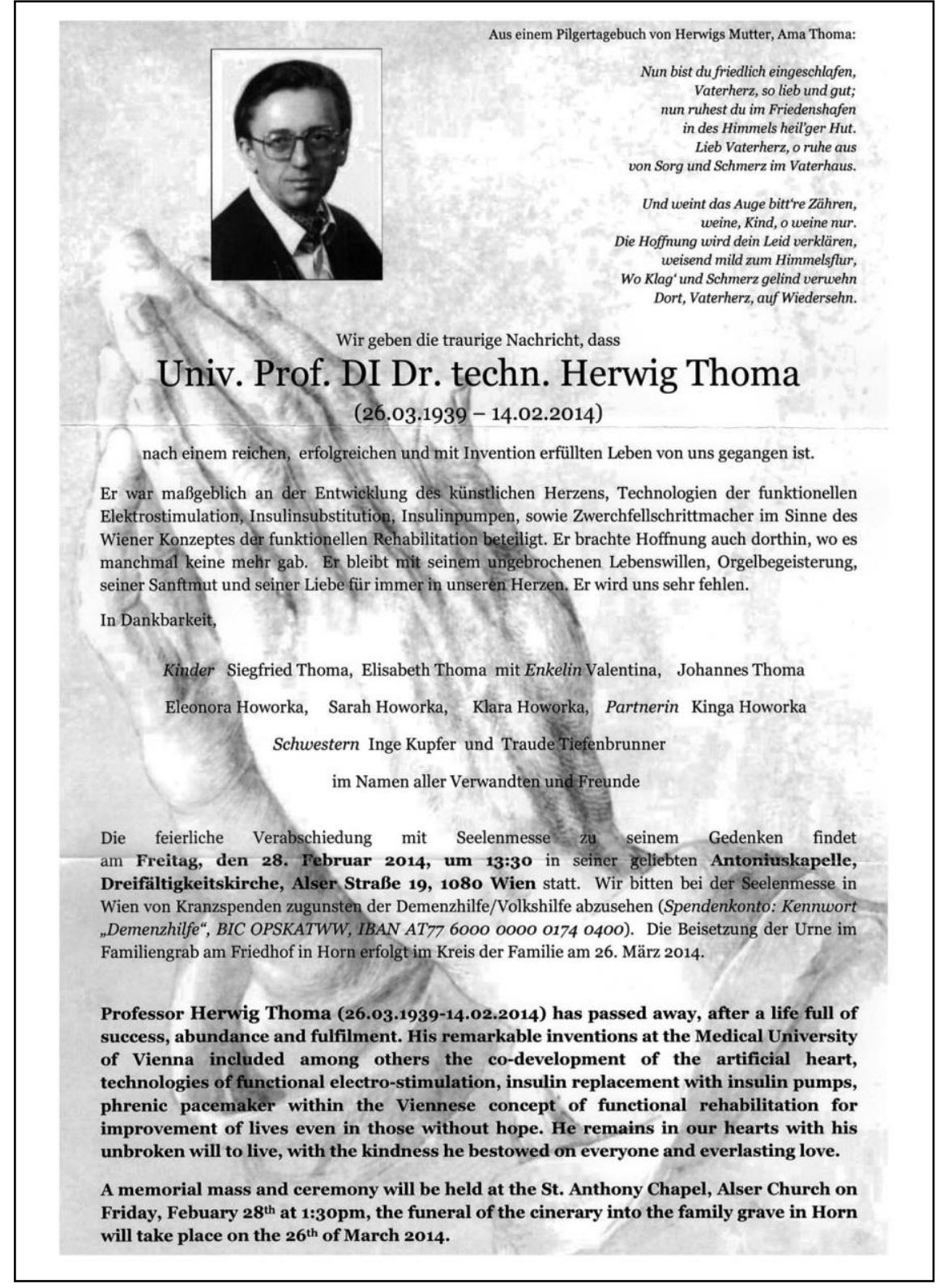

